\title{
Espaço de vida, espaço econômico e as contradições no desenvolvimento regional
}

\section{Life space, economic space and the contradictions in regional development}

Rainer Randolph - Doutor em Ciências Econômicas e Sociais pela Universitat ErlangenNurnberg (Friedrich-Alexander), UEN, Alemanha. Professor da UFRJ atuando como docente permanente nos Programas de Pós-Graduação em Planejamento Urbano e Regional da UFRJ e em Políticas Sociais e Dinâmicas Regionais da UNOCHAPECÓ. E-mail: rainer.randolph@gmail.com

\section{Resumo}

O presente ensaio pretende confrontar problemas da política e do desenvolvimento regional de hoje com uma reflexão sobre a mesma temática de John Friedmann de quase 40 anos atrás. Visa, assim, mostrar a atualidade de um texto antigo deste autor que apresenta sua preocupação com ameaças e desafios fundamentais de então que nomeia as contradições entre território e função e entre espaço de vida e espaço econômico que são objetos de sua reflexão. Posteriormente, visando aprofundar essa discussão, será apresentada uma caracterização de sociedades capitalistas desenvolvida por Habermas para poder aproximar a perspectiva sociológica a uma voltada para manifestações físicogeográficas dos fenômenos. Finalmente, a proposta de Friedmann, que é superar o domínio dos espaços econômicos será situada em relação à sua própria perspectiva de um "planejamento radical".

\section{Palavras-chave}

Desenvolvimento Regional. Contradições. Espaço Vivido. Espaço Econômico. Friedmann.

\begin{abstract}
This essay intends to confront problems of politics and regional development today with a reflection about the same theme of John Friedmann almost 40 years ago. It is intended to show the actuality of a Friedmann's text that presents its preoccupation with the fundamental threats and challenges of the period named as contradictions between territory and function and between the space of life and economic space, which are the object of his reflection. In order to further deepen this discussion, a brief characterization of capitalist societies as developed by Habermas will be presented in order to bring a sociological perspective closer to one geared to physical-geographical manifestations of phenomena. Finally, Friedmann's proposal to overcome the domination of economic spaces will be situated in relation to his own perspective of "radical planning".
\end{abstract}

\section{Keywords}

Regional Development. Contradictions. Living Space. Economic Space. Friedmann. 


\section{INTRODUÇÃO}

Para o número especial de 50 anos da revista Regional Science, um coletivo de autores (TUROK et al., 2017) publicou um artigo sobre trajetória e perspectivas da revista. Referente às recentes mudanças do contexto global e aos extraordinários desafios ao mundo, afirma a importância e a necessidade de pesquisas e estudos regionais e sugere temas para o futuro. Apresentam um diagnóstico a respeito das circunstâncias nas quais a revista foi lançada e do ambiente no qual se encontra hoje: "As circunstâncias mudaram radicalmente desde então. 'Globalização' se soma a muitas tendências influentes, tipificadas pela interligação de regiões e nações por meio de fluxos de comércio, capital, trabalho, tecnologia e informação" (TUROK et al. 2017, p. 1).

Atualmente, uma possível reversão da globalização parece tonar impossível avaliar suas possíveis implicações. Um nacionalismo popular que ressurge em várias partes do mundo - expresso, quase paradigmaticamente, no "America first" do atual governo dos EUA - pode ter profundas consequências para os territórios ao inibir, como alguns dizem, investimento direto, comércio externo e mobilidade de capital social, reduzir o progresso econômico e eliminar oportunidades para as populações mais pobres do mundo; mas forçando mais confiança em produção e competências locais. Outros, de forma alternativa, esperam que na medida que os impulsos patrióticos desafiam estruturas e cartéis globais ossificados, provocam o ressurgimento de empresas regionais e um crescimento orgânico. Bem concebidas as políticas públicas poderiam questionar atuais inércias empresariais e "gerar uma onda schumpeteriana de inovação e criatividade com base na produção em menor escala” (TUROK et al. 2017, p. 2).

Mudanças como a integração global por regiões metropolitanas enquanto nós estratégicos, a transição rural-urbana no Sul Global que mudou a estrutura econômica baseada em agricultura e insumos minerais e os papéis de Estado e mercado em diferentes contextos são um terreno fértil para reflexões teóricas e investigações empíricas (TUROK et al., 2017, p. 2). E, apesar de interrogações válidas a respeito do conceito de regiões, continuam os debates o que são e onde estão; porque e como estão lá; e o que fazem e para quem fazem isso.

Como nunca antes, essas questões ocupam acadêmicos e formuladores de políticas em locais e contextos que demonstram o crescente significado da região em muitos reinos diferentes (PAASI METZGER, 2016). Preocupações básicas relativas à forma como interrogamos regiões e ao desenvolvimento regional permanecem centrais. Um pensamento emergente desafia qualquer noção de que exista uma singular lógica para regiões. É vital que os pesquisadores explorem as razões de ser e formas diferentes 
de tais lugares e construções sociais (AGNEW, 2013) (TUROK et al. 2017, p. 3; tradução e destaque nosso).

Sem entrar aqui numa apreciação das constatações e interpretações dos autores do acima referido artigo, pode-se tirar a conclusão que nem globalização, nem sua possível reversão tornaram obsoletas investigações acerca de desenvolvimento e planejamento regional. Ao contrário, numa situação ainda pouco determinada como a de hoje, além de investigações empíricas para reconhecer a "singular lógica de regiões" -, reflexões teóricas sobre essas temáticas continuam tão necessárias como sempre. E, na medida em que o "curso da história" ainda está a se consolidar e sua compreensão se encontrar num "ponto cego", é mister recuperar aquelas reflexões a respeito de mudanças de suas possíveis lógicas que possam permitir indicar novos caminhos e elaborar propostas para influenciar este "curso" - nada pré-determinado.

Uma dessas reflexões encontramos num texto de John Friedmann, talvez um dos mais conceituados autores da teoria do planejamento, com o título "Life space and economic space: contradictions in regional development" (FRIEDMANN, 1983; 2017a), originalmente apresentado numa Conferência na Suécia em 1981. Antes de entrar no assunto propriamente dito, o autor faz algumas observações sobre o evento que se articulam com o debate do início deste ensaio.

O estudo continua tão atual e pertinente como naquela época quando notou

um esforço quixotesco ... de resistir à corrida impetuosa para abraçar o novo globalismo, que ia significar o apagamento de todas as fronteiras e o triunfo final da economia sobre a política. No fundo da conferência pairava uma ideia que raramente era abordada de frente: uma Europa de regiões, onde o caráter histórico de cada região poderia ter ampla influência num desenvolvimento de acordo com suas próprias tradições. Certamente, houve uma boa parte da conversa habitual sobre as disparidades regionais, mas também um crescente reconbecimento da ação política que se evidencia por meio de movimentos sociais afirmando a autonomia regional 'de dentro' (FRIEDMANN, 2017a; tradução e destaque nossos).

De início, a questão da autonomia de regiões num contexto de um avançado processo de globalização é hoje tão atual como outrora; ao menos na Europa dos movimentos de separação da Catalunha e de outras iniciativas semelhantes.

Mas, mais ainda, além da complexa e contraditória situação do desenvolvimento regional, há outro desafio que se tornou ponto central de preocupações no mundo atual.Não está falando de "teimosas desigualdades regionais" que são um problema, mas que dava para se "viver com isto", como 
disse. $\mathrm{O}$ autor atribuiu uma maior ameaça a um colapso do sistema estatal que dificilmente seria contornado, pois a alternativa mais provável ia ser a menos atraente:

A forma específica desse colapso não é o caos social incipiente, embora seja também isso. É, antes, a tentativa de escorar, pela força, a autoridade cada vez menor do Estado. O fascismo tem sido a resposta histórica aos fracassos da democracia burguesa no gerenciamento das múltiplas crises do mundo capitalista (FRIEDMANN, 2017a; tradução nossa).

E é aqui que se mostra a (infeliz) atualidade da reflexão do autor em relação às recentes mudanças no mundo, apontadas no início deste ensaio. Para Friedmann, caos, fascismo e a possibilidade de lutas sangrentas só podem ser evitados se for reconhecido que estamos sofrendo uma perturbadora confusão de valores.

Portanto, não é a preocupação com desigualdades regionais que determinaram a escolha da abordagem deste seu texto, mas uma profunda preocupação com ameaças e desafios mais fundamentais que ele nomeia de contradições entre território e função e entre espaço de vida e espaço econômico que será trabalhado comum arcabouço dialético que supera os modelos centroperiferia ao introduzir uma "unidade de oposições" entre as duas geografias. Conforme diz, com isto vai retomar uma discussão que já tinha iniciado alguns anos antes (FRIEDMANN, 2017b). Essa perspectiva serve como sustento a sua argumentação e será explicitada na segunda parte do presente trabalho como condição de pensar em alternativas "mais atraentes" da "superação" das contradições do desenvolvimento regional. E foi nesta perspectiva que se inspirou o título do presente ensaio.

Antes disto, num primeiro momento, pretende-se contextualizar mais amplamente as acima mencionadas contradições entre espaço de vida e espaço econômica por uma breve (e, em certa medida, superficial) caracterização das sociedades capitalistas como desenvolvida por Habermas (1981; 1990), especialmente na sua Teoria da Ação Comunicativa.

Com isto obtém-se um duplo ganho:(i) aprofundar a referência geográfica com a incorporação de processos e práticas sociais e políticas; (ii) haverá uma aproximação da perspectiva sociológica a uma abordagem voltada para manifestações físico-geográficas dos fenômenos; o que será demonstrado na parte seguinte do ensaio ao discutir as contradições do planejamento regional.

Finalmente, Friedmann será situado em relação à sua própria perspectiva de "planejamento radical" que também pode ser interpretada em origens habermasianas de contradições e antagonismos entre mundo da vida e sistemas. 


\section{CONTRADIÇÕES ENTRE DIFERENTES LÓGICAS E RACIONALIDADES NA (RE)PRODUÇÃO DE SOCIEDADES CAPITALISTAS}

Como anunciado, o presente trabalho procura aprofundar as acima mencionadas "dialéticas geográficas" das contradições entre território e função por meio de sua contextualização em relação a características gerais das sociedades capitalistas neoliberais contemporâneas. Essas características são derivadas, de forma livre, da ampliação do conceito de "trabalho" para o de "interação" como realizado por Habermas (1990).

Para este autor, apenas a interação permite compreender sociedades humanas na medida em que acrescenta à noção fundamental do trabalho o conceito, igualmente fundamental, da "comunicação". Articulados em diferentes períodos histórico-territoriais de distintas maneiras, comunicação e trabalho (interações) assumem uma determinada expressão histórica em sociedades capitalistas onde dão origem a duas lógicas e dinâmicas não apenas diferentes, mas antagônicas: (i) há uma lógica instrumental da relação dos homens com as coisas que - no caso do capitalismo - instaura a hegemonia do trabalho assalariado sobre outras formas; e (ii) uma lógica comunicativa da relação dos homens com os homens na base da mútua compreensão que é imprescindível para a reprodução social propriamente dita (das tradições, socialização, formação de personalidade) (RANDOLPH, 2015).

Essas lógicas e racionalidades expressam-se (se "institucionalizam") enquanto duas diferentes dimensões ou esferas na sociedade do capitalismo tardio, conforme Habermas (1981). Há um recorte que separa uma esfera de sistemas daquela do mundo da vida (quadro institucional) conforme as acima mencionadas diferentes lógicas vigentes em cada uma delas.

Ao interpretar a noção do sistema a partir de uma matriz conceitual crítica, não funcionalista, como expressão apenas de funções econômicas e administrativas na produção e na reprodução da estrutura da sociedade capitalista, estes podem ser descritas da seguinte forma:

(i) dentro dessa perspectiva, a autonomização da esfera econômica e quase concomitantemente da público-administrativa, dentro de sociedades capitalistas ocidentais, consiste em uma de suas principais características. Por intermédio de um processo de abstração real de relações e processos concretos, os sistemas econômico e administrativo foram se diferenciando e separando das outras 
manifestações e instituições sociais, tornando-se hegemônico (num círculo virtuoso) em relação às demais esferas da vida social e política. Consolidaramse ao submeter à sua própria lógica instrumental-abstrata (do valor de troca) atividades econômicas e administrativas precedentes (por meio da hierarquia como princípio de condução sistêmica). Mais ainda, conseguiram provocar transformações no quadro institucional e infiltrar nele essa lógica instrumental por meio da expansão e da extensão dos mercados e das burocracias (lugar de condução sistêmica da sociedade) em detrimento de valores, normas e motivações originais nessas esferas da vida social. Um processo que pode ser chamado de "colonização". Utilizam-se, para isso, de dinheiro e de poder como meios principais de troca entre sistemas (econômico e burocrático) e quadro institucional. Essas relações serão institucionalizadas, pelos sistemas, por meio de "papéis" no mundo da vida como trabalhador e consumidor - na esfera da economia - e como contribuinte ou cidadão e cliente - na esfera administrativa. Ao mesmo tempo, essa diferenciação consolida o recorte entre uma esfera privada - a da economia e da propriedade privada - e uma esfera pública vinculada à administração e os aparelhos burocráticos do Estado.

(ii) Por seu lado, o quadro institucional da sociedade reúne as condições sociais de reprodução que, historicamente modificadas pelo avanço das esferas sistêmicas, mantém sua própria lógica de articulação, integração e controle social. Chamado de mundo da vida (Lebenswelt), conceito emprestado inicialmente da fenomenologia, rompe-se com a concepção que via a sociedade como um todo constituído de partes, pois

sujeitos socializados comunicativamente não seriam propriamente dito sujeitos se não houvesse a malha das ordens institucionais e das tradições da sociedade e da cultura. O mundo da vida, então, não constitui uma organização à qual os indivíduos pertencem como membros, nem uma associação à qual se integram, nem uma coletividade composta de membros singulares (HABERMAS, 1990, p. 100).

A prática comunicativa cotidiana alimenta-se de um jogo conjunto, resultante da reprodução cultural, da integração social e da socialização, e esse jogo está, por sua vez, enraizado nessa prática. A separação das ações sociais em "privadas" e "públicas" não se deve a uma dinâmica sócio-política intrínseca ao mundo da vida, mas a sua imbricação com os sistemas e com determinadas instituições (por exemplo, a instituição da propriedade). Uma ilustração dessas relações se encontra na Figura 1: 
Figura 1 - Esferas sociais e papéis funcional-sistêmicos

\begin{tabular}{|l|c|c|}
\hline & $\begin{array}{c}\text { Mundo da vida } \\
\text { (quadro institucional) } \\
\text { Trabalhador } \\
\text { Esfera privada }\end{array}$ & Sistemas \\
\cline { 3 - 4 } Esfera pública & $\begin{array}{c}\text { Cliente } \\
\text { cidadão }\end{array}$ & Econômico \\
\cline { 3 - 4 } & & Administrativo \\
\hline
\end{tabular}

Fonte: Randolph (2015).

Essa concepção não tem, a princípio, a ver com uma distinção entre estrutura (econômica) e superestrutura como introduzida por outras abordagens críticas da sociedade capitalista. Na verdade, Habermas não se interessa pelas relações entre os dois "sub"-sistemas que seguem lógicas semelhantes - a economia e o Estado. Em outros contextos, a investigação dessa relação seria muito importante.

\section{ESPAÇO VIVIDO ${ }^{1}$, ESPAÇO ECONÔMICO E CONTRADIÇÕES}

É aqui que o raciocínio de Friedmann pode ser articulado com a abordagem de Habermas. Tanto Habermas quanto ele entendem que a contradição fundamental das sociedades capitalistas contemporâneas se expressa na relação, acima descrita,dos sistemas com o mundo da vida (Habermas) ou do espaço econômico com o espaço vivido/da vida (Friedmann); especialmente por meio do domínio da lógica econômica (instrumental) - abstrata sobre a lógica da vida (comunicativa) - concreta.

Uma lógica, a primeira, que se verifica naquelas relações - inclusive nessas dos homens com os homens - que seguem o "modelo" fundamental da abstração dessas sociedades que é o da mercadoria, da instrumentalização e das estratégias. Contra uma lógica que se encontra naquelas relações entre os homens caracterizadas pelo reconhecimento mútuo, a compreensão e expressão de uma dialética entre os sujeitos e seus objetos (como valor de uso) (RANDOLPH, 2015).

Ao situar a abordagem de Friedmann dentro do acima introduzido arcabouço, percebe-se que o autor privilegiou com relação ao "confronto" entre espaço vivido/mundo da vida privado e economia/sistema econômico a compreensão da dinâmica social e econômica na esfera privada. A "esfera pública" vai entrar na sua argumentação mais tarde na medida em que elabora propostas para "lidar" com as contradições entre estes dois espaços.

A expressão "life space" será traduzida por "espaço de vida" ou "espaço vivido". 
Aí, suas sugestões vão estar relacionadas a ações do Estado (burocracia) que acontecem na esfera pública na medida em que estabelecem, geralmente, relações entre mundo da vida (sociedade civil) e sistemas administrativos ou o Estado(RANDOLPH, 2014; 2015). Apesar da limitação inicial à esfera privada, as conclusões a respeito da expressão da contradição básica em sociedades capitalistas coincidem com a abordagem de Habermas: em consonância com este autor, Friedmann coloca que "nos últimos dois séculos, o espaço econômico vem subvertendo, invadindo e fragmentando os espaços vividos dos indivíduos e das comunidades" (FRIEDMANN, 2017a, tradução nossa).

Em síntese, o posicionamento dos dois autores oferece a possibilidade de articular a démarche do antagonismo entre as duas geografias com aquela do antagonismo entre duas lógicas sócio-políticas. Não será possível realizar isto aqui da forma aprofundada que mereceria; mas estamos convencidos que esse esforço iria contribuir tanto para aprofundar e dar maior abrangência aos argumentos de Friedmann e, com isto, fortalecer sua força de convencimento; como para abrir uma oportunidade de uma "concretização espacial" para a abordagem habermasiana da contradição entre as duas lógicas.

Em primeira aproximação, a concepção de Friedmann em relação à diferença entre os dois termos centrais-espaços vivido (da vida) e econômico - pode ser resumida assim: "O espaço vivido é [...] o teatro da vida, entendido como uma vida convivial e uma expressão dele. O espaço econômico corresponde mais estreitamente às condições de subsistência ou à manutenção da vida" (FRIEDMANN, 2017a).

Quando restrito ao âmbito local, espaços vividos são para Friedmann aqueles da convivência de vizinhos, que podem englobar, como acrescentaríamos, os de famílias. Ao estar constituído pela maioria das atividades diárias das pessoas, estes espaços pertencem à esfera privada ou mesmo à vida num âmbito comunitário limitado. Obviamente, espaços vividos existem em outras escalas. A partir do compartilhamento com outros de práticas conjuntos concretas numa área,a vida acontece também em espaços mais abrangentes como cidade, região e, finalmente, a nação, como diz o autor.

É importante entender que, em qualquer escala, os espaços vividos têm uma extensão territorial limitada, evidenciado em nível nacional. Nessa escala,"onde as fronteiras têm força legal, a limitação é uma característica que, em certa medida, é verdadeira em todos os espaços de vida em qualquer escala" (FRIEDMANN, 2017a). Sem entrar aqui na discussão da "história de um povo" que o autor menciona neste contexto, o espaço vivido naquela concepção mais 
estrita está vinculado a um lugar específico ao qual as pessoas se referem como um lugar particular ou um espaço que importa, com sua própria história e política.

Dentro dessa perspectiva, faz sentido introduzir um desenvolvimento na linguagem dos espaços de vida, como faz o autor. Coerente com o acima mencionado entendimento, com este vínculo entre desenvolvimento com o espaço vivido, o autor propõe uma noção de "desenvolvimento integral que busca alcançar necessidades individuais e coletivas particulares de uma comunidade" (FRIEDMANN, 2017a) e que seria um processo definido a partir de dentro. Por causa disto, seu significado específico varia entre lugares.

As necessidades podem ser entendidas como reivindicações recíprocas e morais, no sentido de que indivíduos podem reivindicar nas suas comunidades a satisfação de suas "necessidades", mesmo que a comunidade, por sua vez, reivindique parte do trabalho do indivíduo como contribuição para as necessidades coletivas (FRIEDMANN, 2017a, tradução nossa).

Com a discussão da relação entre necessidades de indivíduos e de comunidades, Friedmann já aponta para a esfera pública como outro patamar da vida social. Pois, ao entender que necessidades são de natureza finita, elas têm de ser estabelecidas legitimamente em um discurso político. As reivindicações conflitantes precisam ser ponderadas equilibradamente e mediadas em relação aos recursos disponíveis.

Em oposição ao espaço vivido, “o espaço econômico é abstrato e descontínuo, consistindo principalmente de localizações (nós) e ligações (fluxos de mercadorias, capital, trabalho e informação)" (FRIEDMANN, 2017a, destaque e tradução nossos). Enquanto abstrato e ao sofrer contínuas transformações, se constitui historicamente por meio de mudanças que se expressam na linguagem do cálculo diferencial; ou seja, por meio de uma lógica instrumental. É constituído por firmas e corporações como principais atores. Estes visem o lucro por meio da acumulação de excedentes da produção e a seguem o seguinte princípio central: esta acumulação

deve ser privada, enquanto os custos sociais devem ser absorvidos pela conta pública. O critério de escolha formal para as ações produtivas do espaço econômico é, assim, a eficiência na acumulação de um excedente (FRIEDMANN, 2017a, tradução nossa).

Este espaço econômico tem as características de ser aberto, ilimitado com capacidade de se expandir em todas as direções, o que é vivido para a reprodução das relações capitalistas como um todo (FRIEDMANN, 2017a). No seu interior, essa "expansão" significa destruir, sem piedade, produtores ineficientes e sua 
substituição por empresas mais viáveis. A superposição do espaço econômico aos espaços vividos dos indivíduos e das comunidades cria uma ilusão de economias nacionais, regionais e até urbanas.

Parecido com o entendimento da colonização do mundo da vida pelos sistemas (RANDOLPH, 2015) ${ }^{2}$ acima brevemente mencionado, Friedmann observa que, em vez de serem subordinados à vida, os meios de seu sustento se sobrepõem à vida, reduzindo-a a uma função de cálculo econômico. Chama isto uma confusão de valores. Como, esquematicamente, ilustram as relações na Figura 1, na esfera privada a ideologia capitalista iguala a vida ao consumo, o que justificaria o raciocínio (abstrato) que aumentos de renda (e, em consequência, de consumo) gera ganhos na satisfação humana ou na felicidade. "Este é o cálculo da felicidade de recorte utilitário. Em todo o mundo capitalista, a política de desenvolvimento se baseia nele" (FRIEDMANN, 2017a; tradução e destaque nossos).

Para não criar nenhum mal-entendido, Friedmann admite que, sob determinadas condições, haja a possibilidade de uma relação linear entre renda (característica econômico-sistêmico) e felicidade (característica da vida) existir. Isto é, vale para domicílios (conjuntos familiares) até ao ponto de eles chegarem à satisfação de suas necessidades básicas quais, por sua vez, são socialmente determinadas. Fora isto, uma simples relação linear não se sustenta. Um aumento da renda (espaço econômico) não significa necessariamente um incremento da felicidade (espaço vivido). Mas, por outro lado, a perda de trabalho (com redução de renda) pode, ao contrário, reduzir a felicidade por razões não econômicas (preocupação com o futuro etc.).

A maioria dos países ocidentais (e, devo pensar, especialmente os Estados Unidos) parecem já ter ultrapassado o ponto em que as necessidades básicas de todos podem ser supridas pela produção atual, embora este fato seja mascarado pela distribuição muito desigual de renda e riqueza (FRIEDMANN, 2017a; tradução nossa).

Em relação ao raciocínio que vai desenvolver a seguir, o autor esclarece que sua preocupação estará dirigida a situações onde o cálculo do aumento da felicidade não se aplica mais e onde a felicidade depende de outras coisas que do incremento da renda. Onde a continuada subordinação dos valores de vida aos valores de sustento econômico, mesmo para além do patamar das necessidades básicas, tem levado a sérias rupturas que, além de tudo, diminuíram a qualidade das nossas vidas.

2 É esse processo que Habermas (1990), referindo-se a Marx, chama de “colonização" do mundo da vida pelos sistemas que significa uma ameaça permanente de uma instrumentalização de lógicas comunicativas. 
Como se pode compreender isto? Qual é, na opinião do autor, a evidência para isto?

Em primeiro lugar, nota-se nas cidades capitalistas a dissolução dos espaços vividos e sua assimilação progressiva ao espaço econômico.

A cidade capitalista não tem nenhum respeito pela vida: ela invade os bairros para abrir caminho para os negócios; abandona regiões inteiras, porque os lucros são maiores em outro lugar. Privadas de seus espaços vividos, as vidas das pessoas são reduzidas a uma dimensão puramente econômica como trabalhadores e consumidores - pelo menos enquanto houver trabalho (FRIEDMANN, 2017a; tradução e destaque nossos).

Encontramos aqui mais uma prova da articulação das concepções dos dois autores que estão embasando nossa discussão. Ainda mais, como diz Friedmann, essa dinâmica acontece no campo também a cada dia, como se vê na destruição sistemática da terra por desmatamento, erosão, desertificação e outros processos.

Em segundo lugar, a dominação da economia sobre a vida resultou numa compreensão do desenvolvimento, primordialmente, como expansão e crescimento da produção medidos em relação a territórios de nações, regiões ou cidades "em termos estritamente de mercado, sem subtrair os custos sociais da produção" (FRIEDMANN, 2017a, tradução nossa). Destacado pelo autor quarenta anos atrás, mas atual até hoje, essa questão, apesar de ser muitas vezes levantada, precisa ser repetida mais do que nunca em um momento onde os "custos sociais de produção" parecem estar aumentando a uma velocidade vertiginosa. Observa, na época, que seria bem provável que um cálculo mais aprimorado da renda real já mostrasse declínios reais de longo prazo na maioria dos países. Que, por sua vez, subjetivamente, seriam experimentados como declínio da qualidade de vida. "Onde a subsistência triunfa sobre a vida, a implacável busca de crescimento em si conduzirá, em última instância, à destruição da vida" (FRIEDMANN, 2017a; tradução nossa).

Em terceiro lugar, e aqui se encontra a maior proximidade entre nossa discussão referente à dominação dos sistemas sobre o mundo da vida (RANDOLPH, 2014; 2015), o crescimento e as mudanças econômicas se infiltram, pelo capital global, nos espaços vividos de indivíduos e comunidades como uma força externa que

afeta a vida das pessoas, criando novas dependências. Uma forma específica de dependência é a subordinação da força de trabalho local à lógica do capital. Como o capital é extremamente móvel, pode chantagear as comunidades políticas para que aceitem níveis salariais e outras condições de trabalho competitivos no mercado mundial. Os termos dessa barganha inevitavelmente favorecem o capital; eles têm a ver com o sustento de sobrevivência e não com a vida. Os salários são reduzidos 
de US $\$ 10$ para US $\$ 3$ por hora; o trabalho extraordinário é pago na escala regular; e as organizações sindicais estão quebradas (FRIEDMANN, 2017a; tradução nossa).

O autor cita alguns exemplos notáveis para ilustrar esses processos que não serão apresentados aqui. Menciona zonas empresariais que proliferam como "plataformas de exportação" no Terceiro Mundo; ameaças de se deslocar nas primeiras manifestações de descontentamentos dos trabalhadores e outros.

Sua conclusão que "o espaço vivido está sendo colonizado pelo capital, para ser absorvido pelo espaço econômico do sistema mundial" (FRIEDMANN, 2017a; destaque e tradução nossos) coincide com nossas apreciações a respeito das relações entre mundo da vida e sistemas em sociedades capitalistas: como já foi feito por Habermas, denominamos esse domínio dos sistemas sobre o mundo da vida de "colonização" que, por sua vez, dá origem a re-ações pelo mundo da vida em formas de resistência, insurgência, subversão e outras (vide RANDOLPH, 2015).

Em quarto lugar, ao ser assumido pela sociedade (Estado), o aumento, em forma de bola de neve, dos custos sociais de produção levou a uma crise que O'Connor denominou "crise fiscal do Estado"3. Seriam custos relacionados a inflação, desemprego, pobreza crônica, poluição, abandono rural, destruição de antigos centros industriais e mesmo a comportamento criminoso; fenômenos que não podem ser ignorados pelo Estado pois este precisa manter algum equilíbrio entre lealdade voluntária e repressão (na esfera pública). O declínio da lealdade das massas resulta, automaticamente, em aumento da repressão e a preparação de uma luta pelas principais alavancas do poder do Estado.

Mas os problemas persistem. Continuamente gerado por um processo que é cego para as necessidades da vida, o dinheiro pode aliviar alguns dos seus efeitos; não pode destruí-los na sua origem (FRIEDMANN, 2017a; tradução nossa).

Para Friedmann, a crise fiscal do Estado foi - e pode-se dizer - parece ser a expressão das contradições mais profundas do sistema. Com essa análise do Estado e sua crise, o autor avanço da esfera privada - espaço vivido vs. espaço econômico - para a esfera pública na medida em que começa a questionar a disposição dos cidadãos a financiar a intervenção do Estado - como contribuintes, vide Tabela 1 - diante do agravamento das crises econômicas e do aumento da necessidade de financiamentos. E menciona ainda que a intervenção do Estado tende a reduzir os cidadãos em meros "objetos de solicitude" - ou, em outras

Outros autores interpretaram a crise como de "solidariedade", de "legitimidade" etc. 
palavras: cliente, vide Tabela 1 - da burocracia, uma condição da qual podem se ressentir instintivamente. E, de fato, em várias sociedades capitalistas em países industrializados esse "ressentimento" parece ter sido uma das razões para o declínio do apoio ao Estado Social nas décadas de 1970/1980.

E nada mais atual num mundo cada vez mais autoritário e processos democráticos debilitados que a afirmação do nosso autor que "O resultado é uma profunda e disseminada sensação de alienação” (FRIEDMANN, 2017a, tradução nossa).

\section{SUPERANDO A CONTRADIÇÃO ENTRE ESPAÇO VIVIDO E ESPAÇO ECONÔMICO NO DESENVOLVIMENTO REGIONAL?}

Antes de abordar como essas contradições estão ligadas ao desenvolvimento regional, Friedmann (2017a) inicia o trajeto da sua reflexão com um balanço a respeito da elaboração do modelo centro-periferia por Perroux, Myrdal e Hirschman e das contribuições de pensadores marxistas para reformulá-lo.

Estudiosos marxistas deram quatro contribuições principais para a análise regional. Seu ponto de partida teórico é o sistema mundial de relações de mercado. Seus modelos incorporam cada vez mais uma teoria do Estado como um elemento integral. Seu foco é em mecanismos específicos para a transferência geográfica de valor. E sua ênfase política está nos movimentos sociais regionais e suas lutas como instrumento de mudança (FRIEDMANN, 2017a, tradução nossa).

Entretanto, como os marxistas permanecem na sua reflexão num patamar muito abstrato, não conseguem resolver certas ambiguidades e deixam de responder a uma série de perguntas. Ao partir do pressuposto que uma relação centro-periferia envolve conflitantes interesses, o autor pergunta: qual seria a natureza deste conflito? Como entendê-la: entre região e região; entre capital e região? Ou é um conflito, antes de tudo, dentro do próprio capital (entre frações), embora combatido no terreno de regiões - p. ex. capital multinacional confrontado com frações nacionais e regionais da burguesia?

É dentro deste contexto que se inscreve o debate sobre as contradições entre espaço da vida e espaço econômico, entre as duas geografias. Sua perspectiva permite encontrar uma resposta às perguntas acima formuladas para abandonar a dicotomia de centro-periferia.

No passado, como observa Friedmann, o planejamento regional (como uma atividade do Estado) empregou procedimentos incoerentes quando tentou diminuir alguns dos problemas gerados pela violenta invasão dos espaços de vida 
das comunidades historicamente constituídas pelo espaço econômico. E essa incapacidade do planejamento regional de resolver os problemas criados pelas contradições entre os dois espaços, se deu, principalmente, pela

adoção do modelo de espaço econômico: sua preocupação expressa era com as desigualdades espaciais de renda, o desemprego e a adoção de um marco locacional para a análise do subdesenvolvimento regional. Derivada da mesma estrutura, a política regional lidava com incentivos de localização, calculando "multiplicadores" de renda e emprego, bem como "dispersão" por novos investimentos. Da mesma forma, o cenário espacial para a industrialização acelerada, os centros de crescimento foram identificados e ligados em redes cuja estrutura era hierarquicamente arranjada (FRIEDMANN, 2017a, tradução nossa).

Ganhando força no início da década de 1950, essa maciça adoção das forças econômicas e seu "espaço" permanecia incontestado por duas décadas (FRIEDMANN; WEAVER, 1979). As políticas regionais ditas bem-sucedidas implementaram o paradigma do polo de crescimento no qual se basearam

facilitando a importação do crescimento econômico para os espaços de vida das pessoas, integrando regiões e localidades na rede global de relações econômicas com base na desigualdade e intensificando a exploração da força de trabalho, pagando salários pouco competitivos no mercado mundial(FRIEDMANN, 2017a; tradução nossa).

Se for possível questionar até esse "sucesso", em outros aspectos, não obtiveram resultados almejados porque, apesar dos persistentes esforços, a periferia permaneceu periférica; e, em mais do que um caso, o famoso hiato de renda aumentou (STOHR; TODTLING, 1979).

Como a acima apresentada argumentação mostra, a perspectiva de Friedmann sobre problemas e dificuldades de política e planejamento regional não só permite uma compreensão diferente, mas - o que parece mais importante ainda - entender,em toda sua profundidade, porque a saída dessa situação complexa e contraditória não será fácil;pois exige, na opinião do autor, um "reordenamento de valores".

É neste sentido que a aplicação do quadro conceitual indicado neste texto, baseado em Habermas, pode ser útil para acompanhar melhor o raciocínio de Friedmann e compreendê-lo de forma mais profunda e crítica. Porque quando ele propõe a "reordenação de valores" como passo inicial e mais importante, ele se refere exatamente a algumas "estratégias" que nós já esboçamos, mas também descartamos, em trabalhos anteriores (RANDOLPH; FREY, 2018; RANDOLPH, 2016). Esse reordenamento consistiria no seguinte, como ele diz, de forma lapidar: "a vida deve vir primeiro, depois a subsistência (livelyhood)". 
Para isto, em termos práticos, o espaço econômico deve ser subordinado à autoridade política do Estado:

Significa proteger o espaço histórico de vida das cidades, regiões e da nação das incursões cegas do capital. Para estender essa proteção, o Estado deve ter controle sobre as condições básicas de subsistência dentro de um determinado território e exercer esse poder no interesse das pessoas como um todo (FRIEDMANN, 2017a, tradução nossa).

Pois, diferentemente, nós diríamos que o Estado não está necessariamente apto a proteger o espaço vivido na medida em que Estado e burocracia são, eles mesmos, responsáveis para a submissão da lógica comunicativa à lógica instrumental; seria necessário subordinar o espaço econômico ao espaço de vida algo que, como Friedmann diz, teria pouca "praticidade".

Não obstante, Friedmann não entende o Estado como portador de uma lógica instrumental-abstrato. O conceitua como fundamentado numa base de poder muito diferente da atual o que pode parecer tão pouco "prático" como a subordinação do espaço econômico ao espaço da vida. Pois, na sua opinião, para seu sustento (político) o Estado necessitado poder de pessoas, que se mobilizam em prol de uma vida em comum no seu espaço vivido e local de trabalho. No entanto, para o Estado poder responder efetivamente às suas necessidades, "as pessoas devem primeiro recuperar seu poder soberano, revitalizando as comunidades políticas em que vivem" o que pressupõe uma reestruturação das instituições na direção da autogestão e maior autonomia local.

Percebe-se aqui que a contradição entre espaço econômico e espaço vivido, na esfera privada, leva o autor a considerar "espaços públicos" que vão além da mera atuação do Estado (das burocracias). Sugere a formação de assembleias territoriais como caminho para viabilizar a proposta de autogestão e maior autonomia em que os espaços de vida dos indivíduos seriam unidos ao espaço econômico e onde o princípio de delegação substituiria as formas tradicionais de representação de interesses. Imagina que um genuíno discurso público sobre os objetivos do desenvolvimento territorial poderia ser sustentado por meio da agência de tal sistema visto em relação aos meios disponíveis. E, aponta duas condições que precisariam ser satisfeitas para recuperar a comunidade política e os espaços vitais - aqui na sua expressão na esfera pública.

A primeira seria progredir, de forma constante e contínua, em direção a uma "equalização de acesso de domicílios on unidades familiares (housebolds) às bases do poder social' (FRIEDMANN, 2017a; tradução nossa; destaque do autor).

Referências para um progresso neste sentido seriam conhecimento e habilidades pertinentes, organização social e política, instrumentos de produção 
(incluindo o acesso à boa saúde), informações relevantes, redes sociais e meios financeiros. Melhorar o acesso de domicílios a estes assuntos aumentará sua capacidade de perseguir seus próprios objetivos em cooperação com outros. "Nesta visão, a pobreza não é simplesmente uma condição de baixa renda. É uma desigualdade substancial no acesso aos meios para uma vida autônoma dentro da comunidade" (FRIEDMANN, 1979). Neste sentido, um combate gradual da pobreza, um resultado de lutas populares, será experimentado e vivenciado como um movimento libertador da passividade dependente em direção a uma ação política autônoma.

Para introduzir a segunda condição, Friedmann se refere ao conceito da "comunicação não distorcida" (undistorted) de Habermas (1979) o que o aproxima, mais implícita do que explicitamente, do conceito da racionalidade comunicativaconcreta e sua contradição referente à racionalidade instrumental/abstrata. Por ocasião da elaboração do seu artigo, é muito provável que Friedmann não teve acesso à Teoria da Ação Comunicativa cuja versão em alemão foi publicada em 1981. Por isto, a referência ao significado habermasiano da noção de "comunicação não distorcida" por Friedmann é anterior à apresentação dos elementos analíticos usados no presente trabalho. Falar de "comunicação não distorcida" significa, concretamente, uma comunicação quando na referida ação pública as diferenças do poder social pesam excessivamente na troca de significados simbólicos.

A comunicação na política democrática deve ser aberta e multidirecional, refletindo com a maior precisão possível a totalidade dos significados conflitantes. Mas a troca completa e a exploração de significados é um processo demorado, na medida em que a troca dá origem a novos entendimentos, e estes podem levar a ações que, por sua vez, ocasionam uma mais profunda compreensão (insights) sobre o processo e a situação (FORESTER, 1980 apud FRIEDMANN, 2017a, tradução nossa).

Friedmann indica a criação dessas oportunidades como condições para um discurso político genuíno - um verdadeiro desenvolvimento "de dentro" sobre questões de domínio público e espera que a demora deste processo aberto de comunicação reduza as respostas dos órgãos públicos e possa frear o ritmo frenético da mudança impulsionada pela tecnologia.

E chega a conclusão que, obviamente, é exatamente isto o que a reafirmação do domínio da vida sobre a lógica do sustento (livelyhood) e sua tecnologia "autônoma" pretende. Seria dentro de uma comunidade política reestruturada, que o planejamento regional voltaria a encontrar uma missão legítima.

Ajudaria os órgãos políticos a articular suas necessidades e possibilidades de desenvolvimento, fornecer informações pertinentes, projetar imagens 
de possíveis futuros e realizar estudos técnicos específicos para seu cliente, que é a comunidade política em geral e não apenas o Estado central (FRIEDMANN, 2017a, tradução nossa).

Para ele, articulação de necessidades, negociações de programas e relações apropriadas entre os órgãos políticos receberão maior importância e prioridade do que o desejo de uma coordenação abrangente. Uma situação reestruturada sem resolver conflitos baseados em território e classe, que continuarão, será entendida menos como uma luta pelo poder do que como uma forma de aumentar a consciência das pessoas e melhorar as bases de informações do planejamento.

Termina seu texto com a lapidar constatação: "A resolução final do conflito permanecerá política, como é agora". Sem querer mostrar como "superá-la", diga-se de passagem, o passo decisivo para "lidar" com a contradição entre espaços de vida e espaço econômico é o reordenamento de valores, que teria sua expressão na inversão do domínio do espaço da vida sobre o espaço econômico. Sua preocupação com a mudança de valores confere à reflexão do autor sua atualidade. Muitas abordagens sobre dificuldades e desafios enfrentados por política e planejamento regional não os compreendem nessa profundidade para qual o autor chama atenção.

\section{CONTINUIDADES E RUPTURAS: A “TRAJETÓRIA" DA CONTRADIÇÃO ENTRE ESPAÇOS ECONÔMICOS E EPAÇOS DA VIDA}

A própria história do planejamento regional mostra que a subordinação dos espaços econômicos aos espaços vividos (da vida) não ocorreu nestes quase 40 anos após a publicação do texto de Friedmann. Mesmo assim, um confronto entre realidade contemporânea, como superficialmente caracterizada no início deste ensaio, com este "não acontecimento" (ausência) de uma subordinação só comprova como o autor tinha "razão" - se o agravamento da situação desde então é um indício disto.

Isto não quer dizer que não houve esforços de mudanças que, de alguma forma, estavam dirigidos na direção apontada por Friedmann. Ele mesmo, em diferentes momentos na sua obra (FRIEDMANN, 2011), volta a destacar a importância do cotidiano, da prática, da experiência (da vida), da escala local, da sociedade civil e chega a propor um "planejamento radical", cuja realização se daria, em larga medida, na base política de movimentos sociais em comunidades locais que envolvem um número relativamente pequeno de participantes, mas 
com uma perspectiva para além da sua esfera local de ações para maiores mudanças estruturais que precisam ser alcançados em uma escala mais ampla.

É nesta formulação que se reflete não mais a ideia "utópica" da subordinação do espaço econômico (RANDOLPH, 2016), mas o fortalecimento do espaço vivido e a expressão de um "reordenamento de valores" o que coloca aos planejadores radicais três tarefas (FRIEDMANN, 2011): moldar a teoria transformativa às exigências de uma prática de oposição em contextos locais específicos; criando oportunidades para a apropriação crítica de tal teoria por diversos grupos organizados para a ação; retrabalhando essa teoria de maneiras que refletem experiências de primeira mão reunidas no campo da prática em si. Uma "teoria transformativa", para o autor, é um conjunto de complexidades relacionadas às afirmações sobre o mundo que enfoca os problemas estruturais das sociedades capitalistas vistos em um contexto global; fornece uma interpretação crítica das realidades existentes; mapeia, numa perspectiva histórica e prospectiva, o provável curso futuro do problema, assumindo a ausência de lutas transformadoras e contrárias; elabora imagens de um resultado preferido baseado em uma prática emancipatória; sugere a escolha de uma "melhor" estratégia para superar a resistência dos poderes estabelecidos na realização dos resultados desejados.

Menciona, em outros momentos, autores que se tornaram protagonistas, na década de 1980, como o acima mencionado Forester, da elaboração de uma proposta de um planejamento comunicativo em bases habermasianas que vai se tornar na década de 1990 uma das principais vertentes do planejamento público que procura ter um caráter democrático - contra abordagens tecnocratas, instrumentais e abstratas.

O pressuposto de uma, em tendência, "comunicação não distorcida" em processos de planejamento (também regional) é um dos elementos fundantes para essas abordagens de planejamento, sejam comunicativos ou colaborativos. Entretanto, outros autores criticaram essa abordagem da busca por consenso ou, ao menos, consentimentos entre todos os participantes - incluindo os interesses "vividos" - no processo de planejamento porque foi considerado "irreal" ou mesmo inoportuno por estar, implicitamente, fomentando a ideologia neoliberal (RANDOLPH; FREY, 2018).

No entanto e mesmo apesar de certas restrições, no contexto das ideias de Friedmann e dentro da atual discussão sobre contradições entre sistemas e mundo da vida e a dialética entre território e função, essa forma comunicativa continua merecendo nossa atenção porque visava fortalecer a lógica comunicativa-concreta não apenas no âmbito do próprio espaço vivido (conscientização, formação de 
opiniões etc.) mas, também, fora do mundo da vida. Ou seja, aproxima-se às intenções de Friedmann quando este propõe inverter a dominação entre espaço vivido e espaço econômico. Parece difícil, no âmbito das sociedades capitalistas, imaginar a possibilidade de uma inversão entre estes espaços. Mas, como discutido em outro lugar (RANDOLPH, 2015), práticas subversivas efetuadas dentro de uma lógica comunicativa "expandida" 4 poderiam, pelo menos, enfraquecer as lógicas abstratas por meio de ações que não apenas resistem ao processo de colonização do quadro institucional social pelos sistemas, mas procuram expandir a lógica concreta-comunicativa, comprometida com o valor de uso, para as esferas do sistema. Assim, como se poderia dizer, contribuiriam para um "reordenamento de valores".

Na sua investigação das publicações da revista Regional Studies, os autores do acima citado texto (TUROK et al., 2017) identificam temas-chave que foram abordados na revista nos últimos anos e que devem ter, como apontam, alguma influência futuramente. Foram, inclusive, selecionadas contribuições voltadas a essas temáticas para este número especial da revista. Como era de esperar pela lógica da escolha de temas para estudos em desenvolvimento e planejamento regional, essa possível "agenda" para investigações e estudos em desenvolvimento regional significa uma mera continuidade de assuntos e campos de investigação do passado ao contemplar: conceitos e políticas da região, empreendedorismo em contexto regional, geografia da inovação, redes globais, migração e mobilidade, infra-estrutura e desenvolvimento regional e transição para uma economia verde. Ao invés de procurar novas perspectivas e campos temáticos - como demonstrado aqui no texto de Friedmann - pode se ter dúvida se uma simples extrapolação para o futuro vai conseguir dar conta das múltiplas transformações pelas quais o mundo - e as regiões - passam atualmente.

\section{REFERÊNCIAS}

AGNEW, J. A. Arguing with regions. Regional Studies, 47(1), 6-17. 2013.

FORESTER, J. Critical theory and planning practice. Journal of the American Planning Association, vol. 46, p. 275-86. 1980.

FRIEDMANN, J. Life Space and Economic Space: Contradictions in Regional Development. In: FRIEDMANN, J. Life Space and Economic Space: Third World Planning in Perspective. Taylor and Francis. Edição do Kindle, 2017a.

4 As características do planejamento radical são parecidas com aquelas de ações subversivas orientadas por uma lógica comunicativa expandida (RANDOLPH, 2014; 2016). 
FRIEDMANN, J. On the Contradictions Between City and Countryside. In: FRIEDMANN, J. Life Space and Economic Space: Third World Planning in Perspective. Taylor and Francis. Edição do Kindle, 2017b.

FRIEDMANN, J. Insurgencies: Essays in planning theory. London, New York: Routledge, 2011.

FRIEDMANN, J. "Life Space and Economic Space: Contradictions in Regional Development”. In: SEERS, D.; OSTROM, K. (Eds.). The Crises of European Regions. London: Macmillan. 1983.

FRIEDMANN, J. Urban poverty in Latin America, Development Dialogue, vol. 1, p. 98-114. 1979.

FRIEDMANN, J.; WEAVER, C. Territory and Function: The Evolution of Regional Planning. Berkeley: University of California Press; London: Edward Arnold, 1979.

HABERMAS, J. Ações, atos de fala, interações mediadas pela linguagem e mundo da vida. In: HABERMAS, J. Pensamento pós-metafísico. Estudos filosóficos. Rio de Janeiro: Tempo Brasileiro, 1990. p. 65-103.

HABERMAS, J. Theorie des kommunikativen Handelns, Vol. I e II, Frankfurt/M: Suhrkamp, 1981.

HABERMAS, J. Communication and the Evolution of Society. Boston Mass.: Beacon Press, 1979.

PAASI, A.; METZGER, J. Foregrounding the region. Regional Studies, Volume 51, 2017 - Issue 1, 2016.

RANDOLPH, R. A utopia do planejamento e o planejamento da utopia: o longo caminho de um contra-planejamento até o alcance da justiça social. In: XIV Colóquio Internacional de Geocrítica - Las Utopias y la Construccion de la Sociedad del Futuro. Barcelona. Anais... Barcelona: Universidad Barcelona. 2016.

RANDOLPH, R. A origem estrutural da subversão em sociedades capitalistas contemporâneas, suas práticas baseadas na vivência cotidiana e um novo paradigma de um contra-planejamento. In: COSTA, G. M.; COSTA, H. S. de M.; MONTE-MÓR, R. L. de M. (Org.). Teorias e práticas urbanas. Condições para a sociedade urbana. Belo Horizonte: C/Arte, v. 1, 2015. p. 103-127. 
RANDOLPH, R. Subversão e planejamento como "práxis" - uma reflexão sobre uma aparente impossibilidade. In: E. LIMONAD; E. CASTRO. (Org.). Um novo planejamento para um novo Brasil?. Rio de Janeiro: Letra Capital Editora, v. 1, p. 40-57, 2014.

RANDOLPH, R.; FREY, K. Planning and governance: towards radical political approaches In: ERAYDIN, A.; FREY, K. (Eds.) Governance, politics and planning. New York, London: Routledge, no prelo, 2018.

STOHR, W.; TODFLING, F. Spatial equity: some antitheses to current regional development doctrine. In: FOLMER, H.; OOSETRHAVEN, J. (Eds), Spatial Inequalities and Regional Development. Boston, The Hague, London: M. Nijhoff, 1979.

TUROK, I. et al. Global reversal, regional revival?, Regional Studies, 51:1, 1-8, 2017. 
